\title{
EFFECT OF DEXMEDETOMIDINE AS AN ADJUVANT WITH LEVOBUPIVACAINE IN AXILLARY BRACHIAL PLEXUS BLOCK
}

\author{
P. Rajkumar1, K. Murugesan² \\ ${ }_{1}^{1}$ Assistant Professor, Department of Anaesthesiology, Government Mohan Kumaramangalam Medical College, Salem, Tamilnadu. \\ ${ }^{2}$ Associate Professor, Department of Anaesthesiology, Government Mohan Kumaramangalam Medical College, Salem, Tamilnadu.
}

ABSTRACT
BACKGROUND
The surgeries in the upper limb can be done either by general or regional anaesthesia or by the combination of both. ${ }^{1}$ Regional
blockade has wide application in providing surgical anaesthesia and analgesia as well as in treating chronic pain syndromes.
Regional anaesthesia has several advantages in the postoperative period compared with general anaesthesia including decreased
sedation, decreased nausea and vomiting, early discharge from the recovery room and a smooth transition to pain control as the
block effects gradually dissipate. The first demonstration of axillary approach to brachial plexus was done by William Halsted in
1884. He injected cocaine under direct vision. The first percutaneous axillary block was done by G. Hirschel in 1911 . The axillary
approach to brachial plexus blockade provides satisfactory anaesthesia for elbow, forearm and hand surgery. ${ }^{2}$
Aims and Objectives- To evaluate the effect of adding dexmedetomidine as an adjuvant with levobupivacaine in axillary brachial
plexus block and to evaluate the adverse effect and onset time for sensory and motor blockade during analgesia.

\section{MATERIALS AND METHODS}

This prospective, randomised, controlled trial study was conducted in Govt. Mohan Kumaramangalam Medical College, Salem from 2016 - 2017. Ethical committee clearance was duly obtained from the Hospital. For the sake of convenience, it was decided to include 64 subjects in the study with 32 subjects randomised to each of the two study groups. Randomisation of the population is allocated into these defined groups according to computer generated random numbers.

\section{RESULTS}

This study shows the addition of Dexmedetomidine to Levobupivacaine in axillary brachial plexus block results in a shorter onset time for sensory and motor blockade. It also prolongs the duration of sensory and motor blockade and also the duration of analgesia. However, dexmedetomidine use may also lead to bradycardia.

\section{CONCLUSION}

The addition of $1 \mathrm{~mL}$ Dexmedetomidine to $29 \mathrm{~mL}$ of $0.5 \%$ Levobupivacaine in axillary brachial plexus block results in a shorter onset time for sensory and motor blockade. It also prolongs the duration of sensory motor blockade and also the duration of analgesia in patients between 20 years to 50 years of age undergoing forearm and hand surgeries of both sexes.

\section{KEYWORDS}

Axillary Block, Subclavian Artery, Nerve Stimulator.

HOW TO CITE THIS ARTICLE: Rajkumar P, Murugesan K. Effect of dexmedetomidine as an adjuvant with levobupivacaine in axillary brachial plexus block. J. Evolution Med. Dent. Sci. 2018;7(16):1974-1977, DOI: 10.14260/jemds/2018/444

\section{BACKGROUND \\ Brachial plexus block was first performed by two famous} surgeons- Halsted in 1884 and Crile in 1887. Both surgeons first surgically exposed the brachial plexus before applying cocaine to this neural structure under direct vision. The first percutaneous brachial plexus blocks were reported in 1911 by Hirschel and Kulenkampff. Over the ensuing years a variety of techniques, modifications and advancements have made brachial plexus block one of the regional anaesthetic techniques most frequently used in contemporary anaesthesia practice.

'Financial or Other Competing Interest': None.

Submission 06-03-2018, Peer Review 30-03-2018,

Acceptance 05-04-2018, Published 16-04-2018.

Corresponding Author:

Dr. K. Murugesan,

S/o. Kandan, 440/2 Water Board Colony,

Alagapuram, Kattur, Fairlands,

Salem-636016,

Tamilnadu.

E-mail: kmurugesankandan@gmail.com

DOI: $10.14260 /$ jemds $/ 2018 / 444$

(c) $(1)(9)$
Recent work by Winnie has further elucidated the clinically relevant anatomy of the brachial plexus, which has led to further refinement of the technique and recognition of the role of brachial plexus blockin the treatment of sympathetically maintained pain syndromes involving the upper extremity.

The axillary brachial plexus block is typically performed for hand and forearm surgery. This technique of anaesthetising the brachial plexus is considered superior compared to supraclavicular or interscalene blocks. The anaesthesia extends from the mid-arm level down to the hand.

\section{Aim}

To evaluate the effect of adding dexmedetomidine as an adjuvant with levobupivacaine in axillary brachial plexus block.

\section{Objectives}

To evaluate the adverse effect and onset time for sensory and motor blockade during analgesia. 


\section{MATERIALS AND METHODS}

This prospective, randomised, controlled trial study was conducted in Govt. Mohan Kumaramangalam Medical College, Salem from 2016 - 2017. Ethical committee clearance was duly obtained from the hospital. Effects of dexmedetomidine as an adjuvant with levobupivacaine in axillary brachial plexus block patients undergoing forearm and hand surgeries. For the sake of convenience, it was decided to include 64 subjects in the study with 32 subjects randomised to each of the two study groups. Randomisation of the population is allocated into these defined groups according to computer generated random numbers.

- Group L (n= 32) - 29 mL of $0.5 \%$ Levobupivacaine +1 $\mathrm{mL}$ of isotonic sodium chloride solution in axillary brachial plexus block.

- Group LD ( $\mathrm{n}=32)-29 \mathrm{~mL}$ of $0.5 \%$ Levobupivacaine +1 $\mathrm{mL}$ of dexmedetomidine $(100 \mathrm{mcg})$ in axillary brachial plexus block.

\section{Inclusion Criteria}

- ASA I and II patients.

- $\quad$ Age 20 - 50 years.

\section{Exclusion Criteria}

- Patients on adrenoreceptor agonist or antagonist therapy.

- Suspected coagulopathy.

- Infection at the site of block.

- History of respiratory, cardiac, hepatic or renal failure.

- Allergy to local anaesthetics and study drug.

- Pregnant women.

\section{Study Method}

After getting Institutional Ethical Committee approval and written informed consent from patients, the patients were randomly allocated into two groups. Group L $(\mathrm{n}=32)$ was taken as Levobupivacaine group and Group LD $(n=32)$ as Levobupivacaine + Dexmedetomidine group. Patients were not given any premedication before the block.

Axillary block was performed with the patient in the supine position with the upper arm abducted to $90^{\circ}$ and the elbow in $90^{\circ}$ flexion. After local preparation of the area, the axillary artery was palpated and a skin wheal was raised using $2 \mathrm{~mL}$ of lidocaine $2 \%{ }^{3}$ Neural localisation was made using a nerve stimulator. The nerve stimulator was connected to a 22-gauge, $50 \mathrm{~mm}$ long stimulating needle. ${ }^{4}$ The location of the needle was judged adequate when an output current of $0.5 \mathrm{~mA}$ elicited a slight distal motor response. 5 Group L patients $(n=32)$ were given a total $30 \mathrm{~mL}$ solution consisting of $29 \mathrm{~mL}$ levobupivacaine $0.5 \%$ with $1 \mathrm{~mL}$ of isotonic sodium chloride solution. Group LD patients $(n=32)$ were given a total $30 \mathrm{~mL}$ solution consisting of $29 \mathrm{~mL}$ levobupivacaine $0.5 \%$ with $1 \mathrm{~mL}$ volume of $100 \mathrm{mcg}$.

Sensory block for each nerve was assessed by a pinprick test using a 3-point scale. Motor block was evaluated by thumb adduction (Ulnar nerve), thumb abduction (Radial nerve), flexion of the elbow and pronation of forearm (Musculocutaneous) and thumb opposition (Median nerve). Motor block evaluation was done using a modification of the Levvott rating scale ranging from 6 (Normal muscular force) to 0 (Complete paralysis). The onset time of the sensory block was defined as the time interval between the end of the local anaesthetic injection and no response to the pinprick test (Score 2) on all nerve territories. The duration of sensory block is defined as the time interval between the end of local anaesthetic administration and complete resolution of anaesthesia on all four nerves. The onset time of the motor block was defined as the time interval between the end of the local anaesthetic injection and complete paralysis (Score 0). The duration of motor block was defined as the time interval between the end of local anaesthetic administration and the complete recovery of the motor function of the hand and forearm. The duration of analgesia was calculated from the end of local anaesthetic administration to the first analgesia request from the patient.

Postoperatively, pain was assessed by using the Visual Analog Scale.

\section{Statistical Analysis}

The observations were analysed using Epi Info software. Unpaired t-test was applied for demographic data, haemodynamic parameters, onset and duration of sensory/motor blockade and duration of analgesia. Chisquare test was applied for age, sex and ASA grades. P value $<0.05$ was considered as significant.

\section{RESULTS}

A total of 64 patients were enrolled in this study. There were totally 4 cases of block failure, 2 in the levobupivacaine (L) group and 2 in the levobupivacaine + dexmedetomidine group (LD). They were excluded from the study. The mean age of the L group was $34 \pm 7.4$ years and the LD group was $37.1 \pm 9.2$ years. The difference between the two groups are not statistically significant $(p>0.05)$ [Table 1]. The mean onset time for sensory block in Group LD was 9.94 minutes, which was lower than Group L - 10.97 minutes. This was statistically significant $(p<0.05)$. The total duration of analgesia in Group LD was 844 minutes, which was higher than Group L - 658 minutes. This was statistically significant ( $p<0.05$ ). Group LD had lower VAS scores in the $8 \mathrm{H}, 12 \mathrm{H}$ and $16 \mathrm{H}$ when compared to Group $\mathrm{L}$. This was statistically significant $(p<0.05)$. Four cases in LD group had bradycardia, which required treatment with atropine. Side effects such as nausea, vomiting, hypoxaemia and hypotension were not present in both the groups.

\begin{tabular}{|c|c|c|c|c|}
\hline & Mean & SD & P value & T value \\
\hline Group L & 34.00 & 7.469 & & \\
\cline { 1 - 3 } Group LD & 37.167 & 9.229 & 0.149 & 1.461 \\
\hline \multicolumn{4}{|c|}{ Table 1. Comparison of Age Distribution between } \\
the Two Groups \\
\hline
\end{tabular}

The mean age of the L group was $34 \pm 7.4$ years and the LD group was $37.1 \pm 9.2$ years. The difference between the two groups are not statistically significant $(\mathrm{p}>0.05)$.

\begin{tabular}{|c|c|c|c|}
\hline & Male & Female & Total \\
\hline Group L & 17 & 13 & 30 \\
\hline Group LD & 16 & 14 & 30 \\
\hline Total & 33 & 27 & $\mathbf{6 0}$ \\
\hline \multicolumn{3}{|c|}{ Table 2. Comparison of Sex Distribution between } \\
the Two Groups \\
\hline
\end{tabular}

Both the Groups L and LD were comparable, but not statistically significant. 


\begin{tabular}{|c|c|c|c|c|c|c|}
\hline \multirow{2}{*}{} & \multicolumn{2}{|c|}{ Group L } & \multicolumn{2}{c|}{ Group LD } & & \\
\cline { 2 - 7 } & Mean & SD & Mean & SD & P value & T value \\
\hline $\mathrm{PR}$ & 83.400 & 5.430 & 83.267 & 5.388 & 0.924 & 0.0985 \\
\hline $\mathrm{MAP}$ & 93.500 & 6.474 & 92.900 & 6.375 & 0.719 & 0.362 \\
\hline $\mathrm{SPO}_{2}$ & 98.233 & 0.728 & 98.333 & 0.661 & 0.580 & -0.557 \\
\hline \multicolumn{6}{|c|}{ Table 3. Comparison of Baseline Haemodynamic } \\
Variables between the Two Groups \\
\hline
\end{tabular}

The preoperative haemodynamic variables between the two groups were comparable, but not statistically significant.

\begin{tabular}{|c|c|c|c|c|c|c|}
\hline & Group L & \multicolumn{2}{c|}{ Group LD } & & \\
\cline { 2 - 7 } & Mean & SD & Mean & SD & P value T value \\
\hline 5 MINS & 83.900 & 5.189 & 83.433 & 5.380 & 0.734 & 0.342 \\
\hline 10 MINS & 85.233 & 5.380 & 74.933 & 4.226 & 0.001 & 8.246 \\
\hline 15 MINS & 86.667 & 6.013 & 73.900 & 4.221 & 0.001 & 9.518 \\
\hline 20 MINS & 87.600 & 5.922 & 71.667 & 5.707 & 0.001 & 10.610 \\
\hline 30 MINS & 89.167 & 5.427 & 71.333 & 3.898 & 0.001 & 14.618 \\
\hline 45 MINS & 88.800 & 5.774 & 70.167 & 2.902 & 0.001 & 15.794 \\
\hline 60 MINS & 87.900 & 6.525 & 68.867 & 2.636 & 0.001 & 14.814 \\
\hline 90 MINS & 88.500 & 5.551 & 71.367 & 2.619 & 0.001 & 15.290 \\
\hline EOS & 87.667 & 5.492 & 72.633 & 5.707 & 0.001 & 13.483 \\
\hline \multicolumn{7}{|c|}{ Table 4. Comparison of Intraoperative Pulse Rate } \\
between Two Groups \\
\hline
\end{tabular}

Except at $5^{\text {th }}$ minute, the intraoperative pulse rate values were significantly lower in Group LD when compared to Group L. This was statistically significant $(\mathrm{p}<0.05)$.

\begin{tabular}{|c|c|c|c|c|c|c|}
\hline \multirow{2}{*}{} & \multicolumn{2}{|c|}{ Group L } & \multicolumn{2}{c|}{ Group LD } & & \\
\cline { 2 - 7 } & Mean & SD & Mean & SD & P value & T value \\
\hline $1 \mathrm{H}$ & 93.033 & 6.300 & 85.900 & 5.979 & 0.001 & 4.498 \\
\hline $2 \mathrm{H}$ & 93.200 & 6.272 & 90.600 & 6.095 & 0.109 & 1.623 \\
\hline $4 \mathrm{H}$ & 93.100 & 6.418 & 90.500 & 5.979 & 0.156 & 1.436 \\
\hline $8 \mathrm{H}$ & 92.533 & 6.198 & 91.267 & 6.231 & 0.433 & 0.790 \\
\hline $12 \mathrm{H}$ & 92.767 & 6.044 & 91.267 & 6.231 & 0.347 & 0.946 \\
\hline $16 \mathrm{H}$ & 92.833 & 6.035 & 91.500 & 6.191 & 0.402 & 0.845 \\
\hline \multicolumn{6}{|c|}{ Table 5. Comparison of Postoperative Mean Arterial } \\
\multicolumn{8}{|c|}{ Pressure between Two Groups } \\
\hline
\end{tabular}

Postoperative MAP values in Group LD was significantly lower than Group $\mathrm{L}$ in the first postoperative hour ( $\mathrm{p}<0.05$ ). In the $2 \mathrm{H}, 4 \mathrm{H}, 8 \mathrm{H}, 12 \mathrm{H}$ and $16 \mathrm{H}$, the values were not statistically significant.

\begin{tabular}{|c|c|c|c|c|c|c|}
\hline & \multicolumn{2}{|c|}{ Group L } & \multicolumn{2}{c|}{ Group LD } & & \\
\cline { 2 - 8 } & Mean & SD & Mean & SD & P value & T value \\
\hline 1 Hr. & 1.000 & 0 & 1.000 & 0 & 1.000 & 0 \\
\hline 2 Hrs. & 1.000 & 0 & 1.000 & 0 & 1.000 & 0 \\
\hline 4 Hrs. & 2.000 & 0 & 2.000 & 0 & 1.000 & 0 \\
\hline 8 Hrs. & 3.700 & 0.466 & 2.767 & 0.430 & 0.001 & 8.060 \\
\hline $12 \mathrm{Hrs}$. & 5.467 & 0.571 & 4.000 & 0 & 0.001 & 14.060 \\
\hline 16 Hrs. & 6.133 & 0.681 & 5.100 & 0.305 & 0.001 & 7.580 \\
\hline Table 6. Comparison of Visual Analog Scale between Two \\
Groups \\
\hline
\end{tabular}

Group LD had lower VAS scores in the $8 \mathrm{H}, 12 \mathrm{H}$ and $16 \mathrm{H}$ when compared to Group L. This was statistically significant $(\mathrm{p}<0.05)$.

\begin{tabular}{|c|c|c|c|c|}
\hline & Mean & SD & P value & T value \\
\hline Group L & 10.970 & 0.539 & \multirow{2}{*}{0.001} & \multirow{2}{*}{7.366} \\
\hline Group LD & 9.947 & 0.537 & & \\
\hline \multicolumn{7}{|l|}{ Table 7. Comparison of Onset Time for Sensory Block } \\
\hline
\end{tabular}

The mean onset time for sensory block in Group LD was 9.94 minutes, which was lower than Group L - 10.97 minutes. This was statistically significant $(\mathrm{p}<0.05)$.

\begin{tabular}{|c|c|c|c|c|}
\hline & Mean & SD & P value & T value \\
\hline Group L & 11.750 & 0.569 & \multirow{2}{*}{0.001} & \multirow{2}{*}{7.393} \\
\hline Group LD & 10.612 & 0.623 & & \\
\hline \multicolumn{2}{|c|}{ Table 8. Comparison of Onset Time for Motor Block } \\
\hline
\end{tabular}

The mean onset time for motor block in Group LD was 10.61 minutes, which was lower than Group L - 11.75 minutes. This was statistically significant $(p<0.05)$.

\begin{tabular}{|c|c|c|c|c|}
\hline & Mean & SD & P value & T value \\
\hline Group L & 602.833 & 35.808 & \multirow{2}{*}{0.001} & -12.037 \\
\hline Group LD & 720.667 & 39.908 & & \\
\hline \multicolumn{7}{|l|}{ Table 9. Comparison of Total Duration of Sensory Block } \\
\hline
\end{tabular}

The mean time for total duration of sensory block in Group LD was 720 minutes, which was higher than Group L 602 minutes. This was statistically significant $(p<0.05)$.

\begin{tabular}{|c|c|c|c|c|}
\hline & Mean & SD & P value & T value \\
\hline Group L & 491.167 & 32.762 & \multirow{2}{*}{0.001} & \multirow{2}{*}{-113.000} \\
\cline { 1 - 3 } Group LD & 604.167 & 42.530 & & \\
\hline \multicolumn{7}{|c|}{ Table 10. Comparison of Total Duration of Motor Block } \\
\hline
\end{tabular}

The mean time for total duration of motor block in Group LD was 604 minutes, which was higher than Group L - 491 minutes. This was statistically significant $(p<0.05)$.

\begin{tabular}{|c|c|c|c|c|}
\hline & Mean & SD & P value & T value \\
\hline Group L & 658.500 & 35.065 & \multirow{2}{*}{0.001} & \multirow{2}{*}{-18.457} \\
\hline Group LD & 844.33 & 42.563 & & \\
\hline
\end{tabular}

The total duration of Analgesia in Group LD was 844 minutes, which was higher than in Group L - 658 minutes. This was statistically significant $(\mathrm{p}<0.05)$.

\section{DISCUSSION}

In our study, we found that addition of dexmedetomidine to levobupivacaine in axillary brachial plexus block shortens the onset time for sensory and motor block. It also extends the duration of sensory and motor block and also duration of analgesia. Also patients experience lower postoperative VAS scores in the $8 \mathrm{H}, 12 \mathrm{H}$ and $16 \mathrm{H}$. Our study had similar findings with the study by Esmaoglu et al, but in their study they used levobupivacaine $0.5 \% 40 \mathrm{~mL}$ ( $10 \mathrm{~mL}$ for each nerve) along with $100 \mathrm{mcg}$ of dexmedetomidine in axillary block. We used only $7.5 \mathrm{~mL}$ for each nerve and also we found that the onset time for sensory and motor block was a bit longer. Duration of sensory and motor block and total duration of analgesia was a bit shorter in our study when compared to their study. This may be due to the less volume of drug ( $30 \mathrm{~mL}$ ) we used in our study. Our study also shared similar findings with the study by ${ }^{6}$ Kaygusuz et al. They used $40 \mathrm{~mL}(10 \mathrm{~mL}$ for each nerve) of $0.5 \%$ levobupivacaine along with $1 \mathrm{mcg} / \mathrm{kg}$ of dexmedetomidine in axillary block. We used $30 \mathrm{~mL} 0.5 \%$ levobupivacaine with $100 \mathrm{mcg}$ of dexmedetomidine $(7.5 \mathrm{~mL}$ for each nerve). We found that the onset time for sensory and motor block was a bit longer, duration of sensory and motor block and total duration of analgesia was a bit shorter in our 
study when compared to their study. This may be due to the less volume of drug $(30 \mathrm{~mL})$ we used in our study. In their study no cases of bradycardia were reported, but we had 4 cases of bradycardia which required treatment with atropine. This may be due to higher dose $(100 \mathrm{mcg})$ of dexmedetomidine we used in our study. ${ }^{7}$ The alpha- 2 agonists may dose dependently enhance local anaesthetic potency and prolong its duration by combining at the alpha- 2 receptors at peripheral level. ${ }^{8}$ The other possible mechanism by which the alpha- 2 agonists improve local anaesthetic action include- 1), Vasoconstriction around the site of injection, leading to a delay in the absorption of the local anaesthetic and thus a prolongation of the local anaesthetic effect $^{9}$; 2) A direct action on peripheral nerve activity. ${ }^{10}$ Clonidine has been found to inhibit peripheral nerve action directly; 3) Release of local enkephalin like substances; 4) A decrease in the release of local inflammatory mediators; 5) Increase in the release of anti-inflammatory cytokines. ${ }^{11}$ Clonidine and Dexmedetomidine are the currently available alpha-2 receptor agonists. ${ }^{12}$ The usage of clonidine in brachial plexus block with various local anaesthetics yield conflicting results. It was found that clonidine prolongs the motor blockade with mepivacaine and bupivacaine, but not with ropivacaine. The reason for this effect may be because that ropivacaine itself had an intrinsic vasoconstrictor effect and addition of clonidine to ropivacaine did not increase this vasoconstriction effect. Dexmedetomidine was found to be a safe and effective adjuvant in many studies on neuraxial and peripheral nerve blocks. ${ }^{13}$ In a study by Abosedira et al clonidine or dexmedetomidine were added to lidocaine in Bier's block and it was found that dexmedetomidine improved the quality of anaesthesia and analgesia better than that of clonidine. In a study by Kol et al,14 dexmedetomidine and lornoxicam were added to prilocaine in Bier block. They reported that addition of dexmedetomidine had shortened the sensory block onset time and prolonged the sensory block recovery time more than lornoxicam. In 2 other studies by Memis D et $\mathrm{al}^{15}$ and Esmaoglu et al, dexmedetomidinelidocaine mixture was used in Bier block and was found to improve the quality of anaesthesia and reduce postoperative analgesic requirement. ${ }^{16}$ Bajwa et al evaluated the effects of dexmedetomidine and clonidine in epidural anaesthesia. They found that dexmedetomidine is a better neuraxial adjuvant than clonidine to provide an early onset of sensory analgesia and also prolonged postoperative analgesia.

\section{CONCLUSION}

The addition of Dexmedetomidine $(100 \mathrm{mcg})$ to Levobupivacaine $(0.5 \%)$ in axillary brachial plexus block results in a shorter onset time for sensory and motor blockade. It also prolongs the duration of sensory and motor blockade and also the duration of analgesia.

\section{REFERENCES}

[1] Burnham PJ. Simple regional nerve block for surgery of the hand and forearm. J Am Med Assoc 1959;169(9):941-3.
[2] Halaszynski TM. Dexmedetomidine: a look at a promising new avenue of use. Saudi J Anaesth 2012;6(2):104-6.

[3] Coventry DM, Barker KF, Thomson M. Comparison of two neurostimulation techniques for axillary brachial plexus blockade. Br J Anaesth 2001;86(1):80-3.

[4] Guay J. The neurostimulator for brachial plexus blockade by the axillary approach: a metaanalysis on its efficacy to increase the success rate. Ann Fr Anesth Reanim 2005;24(3):239-43.

[5] González-Suárez S, Pacheco M, Roigé J, et al. Comparative study of ropivacaine $0.5 \%$ and levobupivacaine $0.33 \%$ in axillary brachial plexus block. Reg Anesth Pain Med 2009;34(5):414-9.

[6] Kaygusuz K, Gokce G, Gursoy S, et al. A comparison of sedation with dexmedetomidine or propofol during shockwave lithotripsy: a randomized controlled trial. Anesth Analg 2008;106(1):114-9.

[7] Singelyn FJ, Gouverneur JM, Robert A. A minimum dose of clonidine added to mepivacaine prolongs the duration of anesthesia and analgesia after axillary brachial plexus block. Anesth Analg 1996;83(5):104650 .

[8] Singelyn FJ, Dangoisse M, Bartholomee S, et al. Adding clonidine to mepivacaine prolongs the duration of anesthesia and analgesia after axillary brachial plexus block. Reg Anesth 1992;17(3):148-50.

[9] Duma A, Urbanek B, Sitzwohl C, et al. Clonidine as an adjuvant to local anaesthetic axillary brachial plexus block: a randomized, controlled study. Br J Anaesth 2005;94(1):112-6.

[10] Esmaoglu A, Yegenoglu F, Akin A, et al. Dexmedetomidine added to levobupivacaine prolongs axillary brachial plexus block. Anesth Analg 2010;111(6):1548-51.

[11] Masuki S, Dinenno FA, Joyner MJ, et al. Selective alpha2-adrenergic properties of dexmedetomidine over clonidine in the human forearm. J Appl Physiol 2005;99(2):587-92.

[12] Erlacher W, Schuschnig C, Orlicek F, et al. The effects of clonidine on ropivacaine $0.75 \%$ in axillary perivascular brachial plexus block. Acta Anaesthesiol Scand 2000;44(1):53-7.

[13] Abosedira MA. Adding clonidine or dexmedetomidine to lidocaine during Bier's block: a comparative study. J Med Sci 2008;8(7):660-4.

[14] Kol IO, Ozturk H, Kaygusuz K, et al. Addition of dexmedetomidine or lornoxicam to prilocaine in intravenous regional anaesthesia for hand or forearm surgery: a randomized controlled study. Clin Drug Investig 2009;29(2):121-9.

[15] Memis D, Turan A, Karamanlioglu B, et al. Adding dexmedetomidine to lidocaine for intravenous regional anesthesia. Anesth Analg 2004;98(3):835-40.

[16] Bajwa SJ, Bajwa SK, Kaur J, et al. Dexmedetomidine and clonidine in epidural anaesthesia: a comparative evaluation. Indian J Anaesth 2011;55(2):116-21. 